\title{
In the Future, Will There Be Creative Cities in China?
}

\section{Renjie Cai*, Dan Wang}

The School of Architecture of the University of Sheffield, Sheffield S10 2TN, United Kingdom

*Corresponding author: Renjie Cai, 307290911@qq.com

\begin{abstract}
The aim of this paper is to establish the notion of the creative city, show its essential characteristics, and critically evaluate and analyse what elements impact creativity and innovation in cities using real case studies and related literature. Finally, in the essay, the topic of whether or not China will have creative cities in the future is asked, and the feasibility of constructing creative cities in China is discussed, prompting a new way of thinking about China's future creative city plan.
\end{abstract}

Keywords: Creative cities; Chinese cities; Creative Industries Park; Urban policies

Publication date: November 2021; Online publication: November 30, 2021

\section{Introduction}

The idea of the "creative city" was developed and implemented in Western countries three decades ago, but it was not broadly adopted until the beginning of the twenty-first century in cities such as New York, Manchester, and Tokyo (Figure 1.). In truth, Florida's ${ }^{[1]}$ and Landry's ${ }^{[2]}$ also made significant contributions to the promotion of their concepts, while also playing an important role in encouraging the growth of innovative industries in modern cities ${ }^{[3]}$.

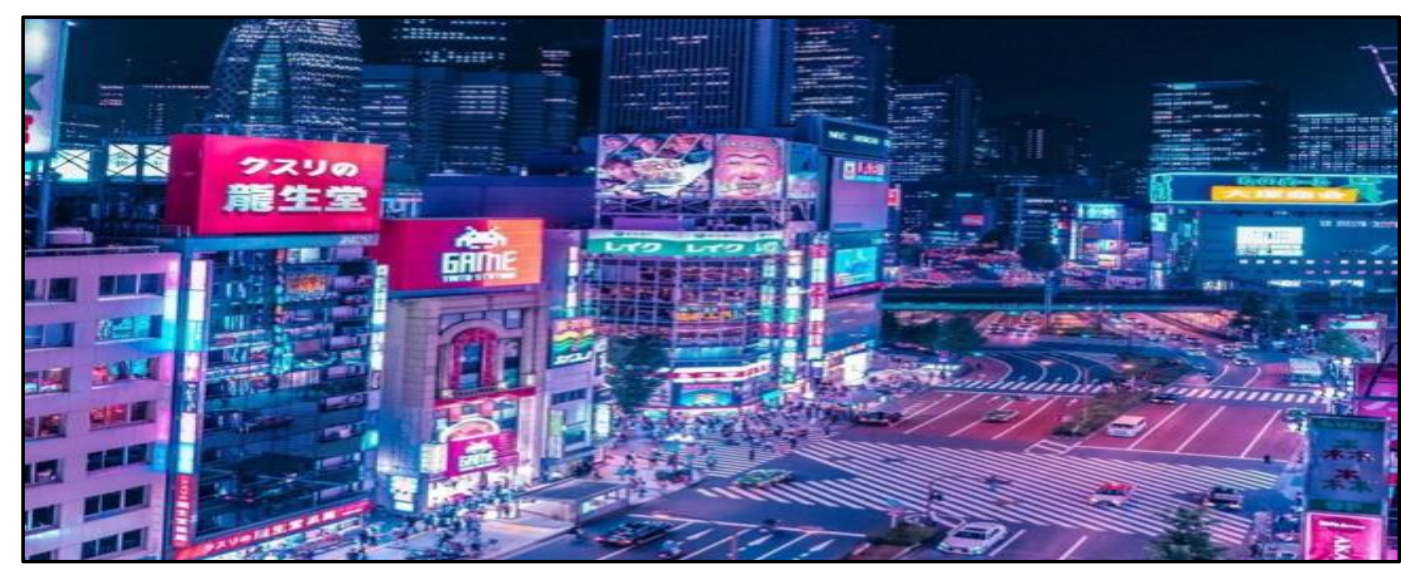

Figure 1. Shinjuku, Tokyo

\subsection{What is a "creative city"?}

The idea of the creative city was first proposed in 1988 by Australian David Lincoln, who outlined it in his essay "The Creative City" written in a literary journal. Since then, it has become a direction for urban planning and urban architecture theorists to research urban growth and gradually develop the practice of creative cities in different Eastern and Western cities. When the principle was first described, David proposed that in order for urban planners and citizens to consider, plan, and behave imaginatively, environments must be created, and resources must be taken advantage of in order to solve some of the challenges of urbanization process. In truth, many examples of cities that use the term "creative cities" only define criteria and conditions that must be fulfilled in order to identify as creative cities; it lacks a precise 
meaning. The meaning provided by $\mathrm{Ch}$. Landry and $\mathrm{Ch}$. Biancini is the most detailed explanation of the term that the author might find.

This is how Landry describes the "creative city": "Great places embody seven elements. They are places of anchorage, they feel like home, there is with a sense of stability, tradition and distinctiveness. They are places of possibility, "can do," stimulation and buzz. They are places of communication and networking, where it is easy connect, interact and move around, the outside world is accessible, and you feel you are part of a bigger, extensive web. They are places to self-improve, learn and reflect. They are places of inspiration. Culture is alive and, finally, a great city is well put together through design" [2].

\section{A case study of Newcastle-Gateshead: "A creative city"}

Newcastle-Gateshead (Figure 2.) is a creative city quarter for commerce, entertainment, and tourism, with a host of music and art-related activities such as classical music performances, concerts, and modern art exhibits taking place. It is not a city on its own, but a cultural and business district created by Newcastle upon Tyne and Gateshead, which was named the UK's arts capital in 2006 according to a study by Artsworld TV channel. In reality, the city has seen cultural investment since the Visual Arts Exhibition in 1996, and the local government has created a cultural district map. Five creative cultural districts have been established, each with creative arts and cultural consumption as a sector, and each with significant public cultural facilities such as cultural institutions, exhibition halls, art halls, and concert halls, as well as providing a cluster of artists and creative workers, and the region is gradually forming a new image as a "creative city" [4].

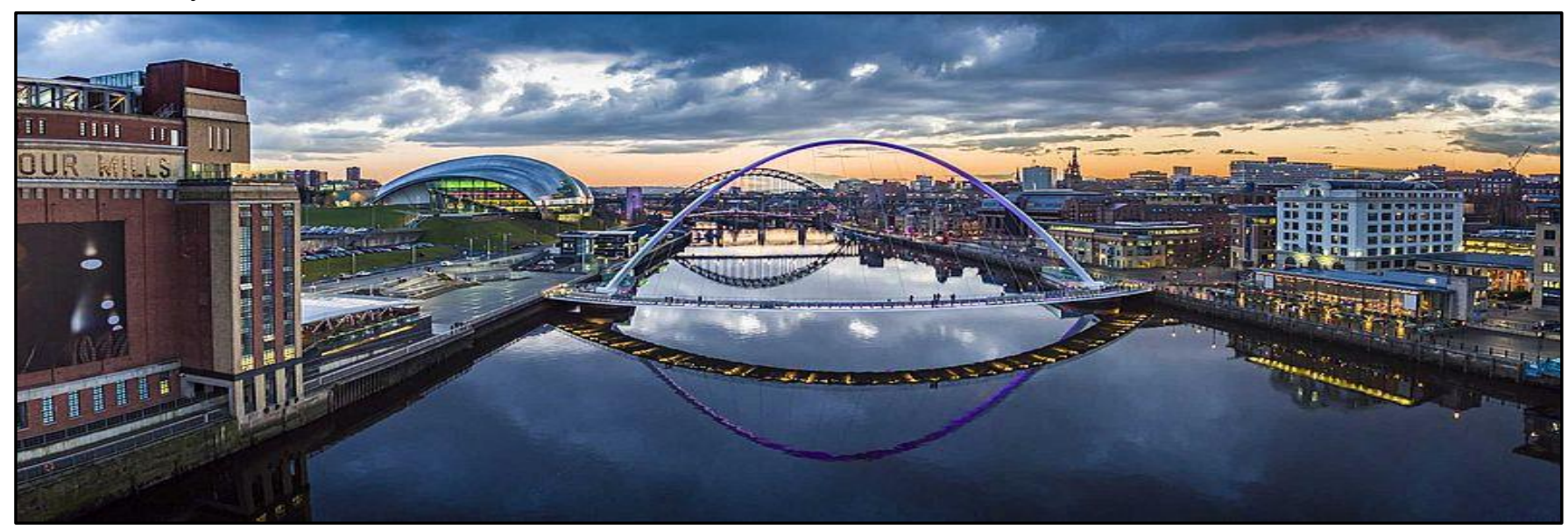

Figure 2. Newcastle Gateshead Quayside, England

\subsection{Literature review}

As previously said, Florida ${ }^{[1]}$ and Landry ${ }^{[2]}$, two scholars who have made major contributions to the growth of creative cities, emphasize differing beliefs in their respective publications and belong to two different creative city models ${ }^{[5]}$. As it is these experts who use a diverse body of expertise from various disciplines to solve particular city problems ${ }^{[6]}$. In a different paradigm, Landry highlights the people, organizations, and public institutions participating in art ventures rather than the experts. Among the variations in the models they advocate, there are some similar characteristics, such as the participation of ambitious people, bold and imaginative organizations, and a political sphere of shared unity of intent, with the state, private, and charitable sectors courageously driving numerous groundbreaking efforts, and even at considerable risk [7].

\subsection{Critical analysis \& summary factors}

The concept of developing a creative community is to think in terms of human society's history, behaviour, 
and personality, and to witness innovative art not only in public sections of the city, but also in private settings, as Shakespeare once remarked. Modern cities require external resources to give the material foundation for inventive city growth, external technology and common skills to bring creative ideas to life, and cultural amenities and art installations to encourage urban community innovation.

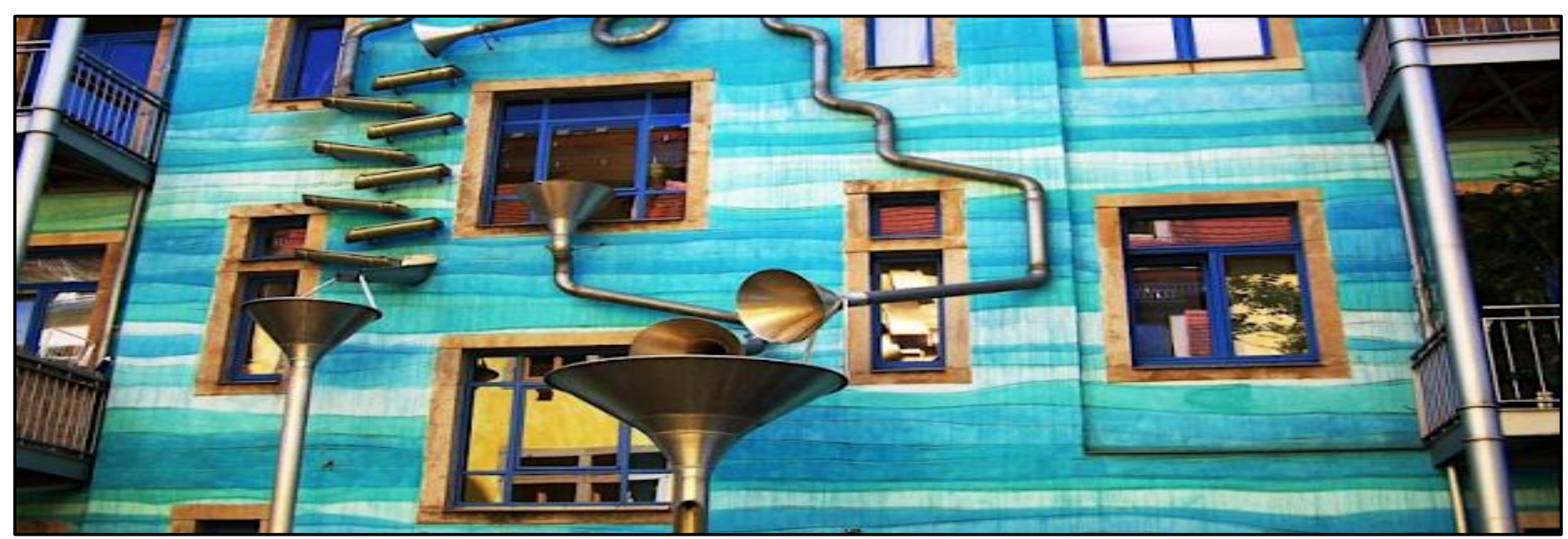

Figure 3. Musical instrument house in Dresden, Germany

At the same time, there are some limitations to the expansion of creative cities. The city's policy of focusing on artistic and cultural items as a way to encourage the regeneration of cultural industries in the city is not controversial in and of itself, but it has resulted in the paradoxical result that these creative cultural industries have pushed up local real estate values, while local low-income residents have seen their real estate values plummet. The second issue is how to alleviate the burden on local workplaces, especially when the creative industries' economic growth is reliant on a cultural tourism market, with a plethora of recreation, entertainment, food and beverage, shopping, and commercial spaces encroaching on creative workers' living rooms ${ }^{[8]}$. Further analysis demonstrates that such a manufacturing structure has an impact on not only different classes of people, but also the expansion of existing independent stores, damaging local neighbourhood development links. Is it conceivable that, because it is a tourism economy, the diversity of the artistic product would be disregarded in order to meet the need for cultural and creative goods? The financial economy will have an impact on the industry as well, such as the appearance of the COVID-19 pandemic in 2020, the global economic crisis, and the severe impact on tourism, all of which will have a direct impact on the consumer market in creative cities.

Landy's methodology summarises the following variables for urban creativity: "Political and public context; Differentiation, variety, energy, and expressiveness; Transparency, trust, access, and participation; Entrepreneurship, exploration, and innovation are three words that come to mind when thinking about entrepreneurship. Strategic vision, agility, and leadership; Talent development and the educational environment; Communication, networking, and connectivity; The location and location-marketing; Affordability and well-being; Effectiveness and professionalism" [9].

\section{Discussions}

\subsection{Is it possible to create creative cities in China?}

Over the last two decades, China's economy has accelerated, particularly in several of its coastal port cities, which are moving from manufacturing to export industries. A variety of proposals and projects from the local arts industry, architects, urban designers, the Shanghai municipal government, and public institutions, including the establishment of a creative industries collaborative and the design of an ambitious industrial park in the new Shanghai district, were adopted based on a survey of city proposals. 
In 2005, the government partly approved the government-led construction of the Creative Industries Park, and subsequent work on implementing a development policy for the concept, which is a really complicated planning project built in phases and by region, began. In 2018, the author visited a creative park in Shanghai that was located in a new district, in a semi-central periphery part of the city, too far from the city center, and with no residential areas nearby, which seemed less friendly to the creative practitioners who worked there. The innovative park is still occupied by art offices and galleries, and new art cultures are being created. Art and art creation, as well as art exchange, architecture, fashion, and textiles, are examples of creative activities; they stimulate innovation and art production in general ${ }^{[10]}$. These creative industries are formed as a result of direct government investment and cooperation with land owners, and can be seen as local government bodies directly facilitating the development of creative industries and constantly regulating the potential development of creative industries in the intended direction through policies and instruments. Historically, creative clusters have been "organic" or "spontaneous," arising from the intersections of the planning regime, the property market, and urban cultural dynamics, and this will undoubtedly continue ${ }^{[7,11]}$, based on the complexities of urban arts and culture, while the Chinese approach appears to be more straightforward and effective, particularly in the early stages, but perhaps this may be a hidden danger later It is also worth thinking about.

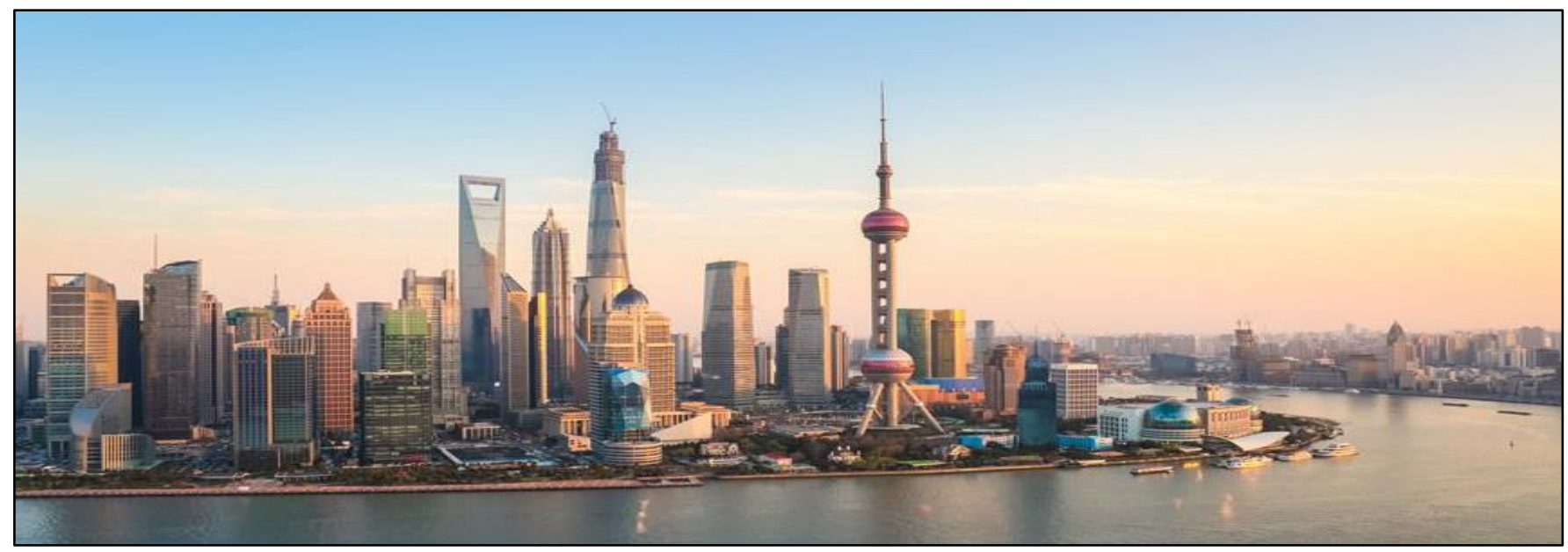

Figure 4. Lujiazui, Shanghai

\subsection{If so, what will it look like?}

According to Pratt ${ }^{[12]}$, "the creative city cannot be like a cathedral in a vast desert: it must be intertwined and interdependent with its cultural context in the same way that we cannot merely use one to grow the other, but must understand the various, nuanced, and integrated cultural-environmental relationships it poses." There is still space for many possibilities to expand, from material production and export to creative product design, from industrial manufacturing zones to creative parks, and from post-industrial cities to creative cities.

Initially on policy and policy level, the current policies formulated in Shanghai, China, by the Government Departments are more preliminary emphasis; new cultural and creative parks are being developed around the town by government funding and the development of parks are being controlled through top-down intervention so that they are not interfered with by external capital. In future, the park's communities will be included as part of the second phase of environmental policy planning and development programs, to enable the park to be accessible entirely to the public and tourists and to include as many residents as possible in the construction of the Artistic Park.

This is because we need to consider the different outcomes of social co-production, for example, new knowledge, new code systems or new urban emotions, and so forth, which may be beyond our expectations. 
Leadership and visionary local politicians should have the expertise to make optimal decisions and to prepare potential solutions. Creative parks cannot be limited to a specific area but should be comprehensively and coordinately built in the center of the city, perhaps reusing the remaining urban public space and transforming it into a new place for collective practice ${ }^{[13]}$. Perhaps a multi-center space for art and cultural creativity in the city could be created. Based on the lessons learned from the NewcastleGateshead event, particularly the limitations raised in the previous section, the original network of community connections can be remained and to create the inclusive urban environment for cultural and artistic innovation.

Second, Shanghai has been adopting health and welfare policies for the management of human capital, providing inventive people with a convenient and secure environment in which to explore and create in culture and the arts. There are also new professional and effective network platforms that use technology to promote formal peer-to-peer and point-to-multipoint networks in order to improve communication and develop networks between cultural practitioners.

\section{Disclosure statement}

The author declares no conflict of interest.

\section{References}

[1] Florida R, 2002, The Rise of the Creative Class: And How It's Transforming Work, Leisure, Community and Every day, Life New York: Basic Books.

[2] Landry C, 2000, The Creative City: A Toolkit for Urban Innovators, London: Earthscan Publications.

[3] Canniffe E, 2017, Business as Usual: Creativity in Manchester's Neoliberal Regeneration, in: ACTAS ICONO14 - V Congresso Internacional Cidades Criativas | 25-27 Janeiro 2017. Porto-Portugal, 45-55, “North East voted 'arts capital'." BBC News. 29 December 2006. Retrieved 18 August 2007.

[4] Comunian R, 2011, Rethinking the Creative City: The Role of Complexity, Networks and Interactions in the Urban Creative Economy. Urban Studies, 48(6): 1157-1179. https://doi.org/10.1177/0042098010370626

[5] Miles M, 2013, A Post-Creative City?, RCCS Annual Review, 5.

[6] Mommaas H, 2004, Cultural Clusters and the Post-Industrial City. Urban Studies, 41(3): 507-532.

[7] Delsante I, 2017, The Notion of the Creative City and its Implementation in Shanghai, China: Spatial practices and Further Implication for Design Actions. La Città Creativa; Rome: BISP, 323-331. https://www.academia.edu/download/54900839/The-notion-of-the-creative-city.pdf

[8] Lange B, 2005, Socio-Spatial Strategies of Culturepreneurs. The Example of Berlin and Its New Professional Scenes, Zeitschrift fur Wirtschaftsgeographie, 49: 79-96.

[9] Szczech E, 2014, Is there a Creative City in Poland? Defining and Measuring the Concept in Poland. Prace Naukowe Uniwersytetu Ekonomicznego We Wrocławiu, 334. https://doi.org/10.15611/pn.2014.334.23

[10] Ren X, Sun M, 2012, Artistic Urbanization: Creative Industries and Creative Control in Beijing, International Journal of Urban and Regional Research, 36(3): 504-521.

[11] Mommaas H, 2009, Spaces of Culture and Economy: Mapping the Cultural- Creative Cluster Landscape. Creative Economies, Creative Cities. Netherlands: Springer. 45-59.

[12] Pratt A, 2008, Creative Cities? Urban Design, Spring 106: 35.

[13] Evans G, 2009, Creative Cities, Creative Spaces and Urban Policy. Urban Studies, 46(5-6): 1003-1040. 